\title{
A Case Report of Malignant Hyperthermia in a Young Male Veteran Diagnosed with an Early Rise of $\mathrm{ETCO}_{2}$ during Shoulder Arthroscopy
}

\author{
Sajid Mahmood ${ }^{1}$, Mahwash Siddiqui ${ }^{1}$, Karen Carvajal ${ }^{1}$ and Amin Ur Rehman Nadeem ${ }^{2}$ \\ ${ }^{1}$ Department of Internal Medicine, Rosalind Franklin University of Medicine and Science, USA \\ ${ }^{2}$ Department of Internal Medicine and Critical Care, Rosalind Franklin University of Medicine and Science, USA
}

Submission: January 19, 2017; Published: January 25, 2018

*Corresponding author: Sajid Mahmood, Department of Internal Medicine, Rosalind Franklin University of Medicine and Science, USA, Email: drsajid@live.com

\begin{abstract}
Malignant hyperthermia (MH) is a chain reaction of symptoms triggered in susceptible individuals by commonly used inhalational agents and also muscle relaxants such as succinylcholine [1]. We describe a case of malignant hyperthermia in a young male diagnosed with earliest rise in $\mathrm{ETCO}_{2}$ concentration. A 37-year-old male underwent right shoulder arthroscopy due to labral tear. Patient was intubated with use of succinylcholine and propofol, general anesthesia was given with sevoflurane. Within 10 minutes of anesthesia, patient developed hypoxemia and $\mathrm{ETCO}_{2}$ started rising, minute ventilation was increased with $100 \%$ oxygen, yet $\mathrm{ETCO}_{2}$ raised to maximum level of $80 \mathrm{mmHg}$. Initially, it was thought that patient is suffering from bronchospasm and was treated accordingly. Patient condition did not improve and within an hour he developed signs like hypercarbia, tachypnea, tachycardia, hyperthermia, and laboratory findings of hyperkalemia, rhabdomyolysis were noticed. Sevoflurane was stopped immediately; further management was done with intravenous dantrolene along with D50W, Insulin and nebulized albuterol. Surgical procedure was completed with intravenous propofol. MH expert was consulted over hotline. Patient had complete recovery and was discharged from hospital without any significant sequelae. This case demonstrates significance of monitoring ETCO $_{2}$ concentration for early identification and management of this life-threatening condition.
\end{abstract}

Keywords: Malignant hyperthermia; $\mathrm{ETCO}_{2}$; Shoulder arthroscopy; Succinylcholine; Veteran

Abbreviations: ETCO : End-Tidal Carbon Dioxide; D50W: Dextrose Water 50\%; ICU: Intensive Care Unit; MH: Malignant Hyperthermia

\section{Introduction}

Malignant hyperthermia $(\mathrm{MH})$ is a chain reaction of symptoms that are triggered in susceptible individuals by commonly used inhalational agents such as halothane, enflurane, isoflurane, sevoflurane and also muscle relaxants such as succinylcholine. The symptoms of MH include a greatly increased body metabolism, high fever and muscle rigidity $[1,2]$. Following is the case of malignant hyperthermia in a young male diagnosed with earliest rise in $\mathrm{ETCO}_{2}$ concentration.

\section{Clinical Objective}

Our case demonstrates the efficacy and significance of monitoring $\mathrm{ETCO}_{2}$ concentration for early identification and management of malignant hyperthermia, a life-threatening condition.

\section{Case Report}

A 37-year-old Caucasian male veteran had elective arthroscopy of right shoulder due to labral tear at our health care facility. Patient was induced with propofol and succinylcholine, general anesthesia was maintained with sevoflurane. After few minutes into procedure, oxygen saturation dropped to
$69 \%$ along with rise in $\mathrm{ETCO}_{2}$; initially bronchospasm was considered, so patient was hyperventilated, nebulized albuterol was administered, saturation improved to 90s. Other concerning clinical issues encountered were development of tachycardia, hyperthermia and rise in $\mathrm{ETCO}_{2}$ despite attempts to increase minute ventilation. Due to presence of these findings diagnosis of malignant hyperthermia was strongly considered. Dantrolene was administered empirically. Sevoflurane was stopped and switched over to propofol infusion. Laboratory findings include hyperkalemia $(\mathrm{K}=6.7)$, lactic acidosis ( $\mathrm{LA}=3.9)$, elevated $\mathrm{CPK}$ and myoglobin levels $(114,806 \& 61,900$ respectively) and arterial blood gases consistent with acute hypercarbic respiratory failure. Patient was treated with intravenous 50\% dextrose, insulin, $\beta$-2agonist nebulization and dantrolene. Patient had adequate clinical response with resolution of tachycardia and improvement in $\mathrm{ETCO}_{2}$ to 30s. Patient also had arterial and foley's catheter placed. Patient was also noticed to have tea colored urine which was thought to be secondary to rhabdomyolysis. Surgical procedure was completed and he was transferred to the ICU for further care. In ICU patient management was done in consultation with expert from malignant hyperthermia hotline. Patient was aggressively hydrated with intravenous 


\section{Juniper Online Journal of Case Studies}

normal saline and also received intravenous dantrolene every 6 hours for 48 hours. Patient condition was significantly improved by day third in ICU; dantrolene was discontinued to avoid unnecessary muscle relaxation. Patient was extubated on day third, he complained of pain in left arm which was thought to be secondary to rhabdomyolysis. He was later transferred to medical floor and was discharged from hospital in stable condition.

\section{Discussion}

During an acute event of malignant hyperthermia, intracellular calcium increases in skeletal muscle, causing uncontrolled muscle contractions. The ryanodine receptor (RYR1) gene encodes the key channel which mediates calcium release in skeletal muscle during excitation-contraction coupling, and mutations in this gene are considered to account for susceptibility to MH (MHS) in more than $50 \%$ of cases [3].The aberrant receptor once triggered by specific agents like in this case by (succinylcholine [4]/ sevoflurane) or other halogenated inhalation agents, allows release of excess calcium into the cytosol of skeletal muscle. This patient had no previous history of allergies but developed symptoms of malignant hyperthermia after receiving sevoflurane and succinylcholine.

In this case, increase in concentration of exhaled carbon dioxide $\left(\mathrm{ETCO}_{2}\right)$ served as an earliest sign of malignant hyperthermia. Multiple other signs of hypermetabolic activity observed throughout the event included tachycardia, tachypnea, hyperthermia and respiratory acidosis. Hyperthermia is a proportionally late sign and temperature was not spiked high in our case. Lyses of overactive muscle cells turns out in releasing of intracellular potassium and the resultant hyperkalemia can induce fatal cardiac dysrhythmias. Subsequently, the enormous release of cellular contents creates electrolyte disturbances, further increases metabolic acidosis as well as myoglobinuria. It can also lead to significant renal failure [5].

Successful management of the acute MH episode involves early diagnosis with immediate and early administration of dantrolene [6]. In 1975 Harrison et al. [7] first described that dantrolene could be effective in treatment of malignant hyperthermia. The mortality rate from $\mathrm{MH}$ was reduced from $80 \%$ to $10 \%$ following the development of dantrolene [7] Dantrolene sodium inhibits the release of calcium from the SR by binding to RYR1 and reverses the effects of MH i.e. uncouples depolarization with contraction. Fast contracting twitch muscles are affected more than slow contracting antigravity muscles. In contrast to pronounced effects on skeletal muscle, effects of dantrolene on cardiac muscle contractility are mild or absent [8]. The recommended dose of dantrolene is $2-3 \mathrm{mg} / \mathrm{kg}$ every 5 minutes, up to a total dose of $10 \mathrm{mg} / \mathrm{kg}$ if needed [5]. This patient underwent a rapid improvement with the initial dose of dantrolene.

In addition to dantrolene, other immediate interventions include discontinuation of the triggering agents. Hyperthermia should be treated by internal cooling with cold infusion fluids and external surface cooling with ice packs placed in the axillae and groin or specific cooling devices until body temperature reaches $38.5^{\circ} \mathrm{C}$ [9]. In our case, patient was hyperventilated with 100\% 02 to compensate for the increased metabolic oxygen demand. Serial arterial blood gases were drawn to assess and watch metabolic acidosis, electrolyte imbalances, and other markers release during muscle metabolism. To treat hyperkalemia with potassium level of 6.7, EKG changes consistent with hyperkalemia were noted and he was empirically given Insulin and dextrose. Sodium bicarbonate was also given to treat metabolic acidosis. In order to manage malignant hyperthermia, high suspicion to recognize early symptoms is of particular importance. An abrupt rise in end tidal $\mathrm{CO}_{2}$ may occur simultaneously with administration of succinylcholine $[10,11]$. In this case, anesthesiologist noted early rise in $\mathrm{ETCO}_{2}$ and promptly intervention was done as evidenced by the absence of morbidity and minimal changes in laboratory values. After stabilization and completion of procedure, he was admitted to intensive care unit for 72 hours to monitor any complications as well as possible recrudescence of symptoms. MH hotline was also called to consult MH expert.

Interestingly, there are some reports of fulminant $\mathrm{MH}$-like episodes occurring in the absence of anesthetic agents. $\mathrm{MH}$ episodes in the wake state have been described after excessive alcohol consumption, drug abuse, and extreme emotional and physical stress [12-14]. While genetic testing is under development, a muscle biopsy test is the final confirmation of malignant hyperthermia susceptibility $[6,15]$. For about 30 years, the in vitro contracture test using halothane and caffeine has been the gold standard for determining susceptibility to $\mathrm{MH}$ independent of a clinical MH event. Following a surgical muscle biopsy, live muscles specimens are exposed to defined concentrations of halothane or caffeine. If developing contracture forces exceed given thresholds after exposure to halothane and/or caffeine, the patient is diagnosed to be MHS (susceptible). Absence of development of significant contracture following exposure to these agents leads to a diagnosis of MHN (non-susceptible) [16]. Since MH is an autosomal dominant with variable penetrance, testing is also recommended for family members of patients with a positive contracture test. For our patient and MH-positive family members, non-triggering anesthesia should be used for surgeries in future. Even without a positive history of $\mathrm{MH}$, any physician using potent inhalation anesthetics or succinylcholine must be prepared to treat $\mathrm{MH}$ Dantrolene and sterile water for injection must be promptly accessible. Further information can be obtained at the Web site for Malignant Hyperthermia Association of the United States (MHAUS) and by calling their emergency 24 hour hotline at 1-800-644-9737 [17].

\section{Conclusion}

Our case draws attention to any physician using potent inhalational anesthetics or succinylcholine; must be prepared to treat $\mathrm{MH}$ and risks should always be considered high even in patients without positive history of malignant hyperthermia. 


\section{Juniper Online Journal of Case Studies}

Additionally, it also demonstrates the efficacy and significance of monitoring $\mathrm{ETCO}_{2}$ concentration for early identification and management of this life threatening condition. MH emergency hotline contact number should be saved at readily accessible place to make call in timely manner.

\section{References}

1. Shulman M, Braverman B, Ivankovich AD, Gronert G (1981) Sevoflurane triggers malignant hyperthermia in swine. Anesthesiology 54(3): 259260

2. Allen GC, Brubaker CL (1998) Human malignant hyperthermia associated with desflurane anesthesia. Anesth Analg 86(6): 13281331.

3. McCarthy TV, Quane KA, Lynch PJ (2000) Review Ryanodine receptor mutations in malignant hyperthermia and central core disease. Hum Mutat 15(5): 410-417.

4. Hopkins PM (2011) Malignant hyperthermia: pharmacology of triggering.Br J Anaesth 107(1): 48-56.

5. Fukami MC, Ganzberg SI (2005) A case report of malignant hyperthermia in a dental clinic operating room. Anesth Prog 52(1): 24-28.

6. Rosenbaum HK, Miller JD (2002) Malignant hyperthermia and myotonic disorders. Anesthesiol Clin North America 20(3): 623-664.

7. Strazis KP, Fox AW (1993) Malignant hyperthermia: a review of published cases. Anesth Analg 77(2): 297-304.
8. Fratea S, Langeron O, Lecarpentier Y, Coria P, Riou B (1997) In vitro Effects of Dantrolene on Rat Myocardium. Anesthesiology 86: 205-215.

9. Glahn KP, Ellis FR, Halsall PJ, Müller CR, Snoeck MM. (2010) Recognizing and managing a malignant hyperthermia crisis: guidelines from the European Malignant Hyperthermia Group.Br J Anaesth 105(4): 417420.

10. Rosenberg H, Davis M, James D, Pollock N, Stowell K (2007) Malignant hyperthermia. Orphanet J Rare Dis 2: 21.

11. Tautz TJ, Urwyler A, Antognini JF, Riou B (2010) Case scenario: Increased end-tidal carbon dioxide: a diagnostic dilemma. Anesthesiology 112(2): 440-446.

12. Capacchione JF, Muldoon SM (2009) The relationship between exertional heat illness, exertional rhabdomyolysis, and malignant hyperthermia. Anesth Analg 109(4): 1065-1069.

13. Wappler F (2010) Anesthesia for patients with a history of malignant hyperthermia. Curr Opin Anaesthesiol 23(3): 417-422.

14. Wappler F, Fiege M, Steinfath M, Agarwal K, Scholz J, et al. (2001) Evidence for susceptibility to malignant hyperthermia in patients with exercise-induced rhabdomyolysis. Anesthesiology 94(1): 95-100.

15. Rosenberg H, Antognini JF, Muldoon S (2002) Testing for Malignant Hyperthermia. Anesthesiology 96: 232-237.

16. Larach MG (1989) Standardization of the caffeine halothane muscle contracture test. North American Malignant Hyperthermia Group. Anesth Analg 69(4): 511-515.

17. (2017) Malignant Hyperthermia Association of the United States (MHAUS).

\section{Your next submission with Juniper Publishers will reach you the below assets}

